\title{
ARTICLE \\ Ganoderic acid A protects neural cells against NO stress injury in vitro via stimulating $\beta$ adrenergic receptors
}

\author{
Zi-ru Yu ${ }^{1}$, Wei-hua Jia ${ }^{1}$, Chao Liu ${ }^{1}$, Hong-qing Wang ${ }^{1}$, Hai-guang Yang ${ }^{1}$, Guo-rong He ${ }^{1}$, Ruo-yun Chen ${ }^{1}$ and Guan-hua Du ${ }^{1}$
}

\begin{abstract}
Excessive nitric oxide (NO) causes extensive damage to the nervous system, and the adrenergic system is disordered in many neuropsychiatric diseases. However, the role of the adrenergic system in protection of the nervous system against sodium nitroprusside (SNP) injury remains unclear. In this study, we investigated the effect of ganoderic acid A (GA A) against SNP injury in neural cells and the role of adrenergic receptors in GA A neuroprotection. We found that SNP $(0.125-2 \mathrm{mM})$ dosedependently decreased the viability of both SH-SY5Y and PC12 cells and markedly increased NO contents. Pretreatment with GA A $(10 \mu \mathrm{M})$ significantly attenuated SNP-induced cytotoxicity and NO increase in SH-SY5Y cells, but not in PC12 cells. Furthermore, pretreatment with GA A caused significantly higher adrenaline content in SH-SY5Y cells than in PC12 cells. In order to elucidate the mechanism of GA A-protecting SH-SY5Y cells, we added adrenaline, phentolamine, metoprolol, or ICI $1185511 \mathrm{~h}$ before GA A was added to the culture medium. We found that addition of adrenaline (10 $\mu \mathrm{M})$ significantly improved GA A protection in PC12 cells. The addition of $\beta 1$-adrenergic receptor antagonist metoprolol $(10 \mu \mathrm{M})$ or $\beta 2$-adrenergic receptor antagonist ICI $118551(0.1$ $\mu \mathrm{M})$ blocked the protective effect of GA A, whereas the addition of a-adrenergic receptor antagonist phentolamine (0.1 $\mu \mathrm{M})$ did not affect GA A protection in SH-SY5Y cells. These results suggest that $\beta$-adrenergic receptors play an important role in the protection of GA A in SH-SY5Y cells against SNP injuries, and excessive adrenaline system activation caused great damage to the nervous system.
\end{abstract}

Keywords: $\beta$-adrenergic receptors; sodium nitroprusside (SNP); SH-SY5Y cells; PC12 cells; ganoderic acid A; adrenaline; norepinephrine; phentolamine; metoprolol; ICI 118551

Acta Pharmacologica Sinica (2020) 41:516-522; https://doi.org/10.1038/s41401-020-0356-z

\section{INTRODUCTION}

Nitric oxide (NO) injury can lead to various neurological diseases, such as Alzheimer's disease [1] and Parkinson's disease [2, 3]. Sodium nitroprusside (SNP) is a donor of NO [4] and is widely used to induce NO damage in models. Currently, SNP injury mechanisms include mitochondrial damage [5], calcium overload [6], and the promotion of apoptosis and more specifically involve the glycogen synthase kinase 3/mitogen-activated protein kinase signaling pathway [7] and reactive oxygen [8]. However, the role of neurotransmitters of the adrenergic system in the regulation of the nervous system in vivo is unknown, and the effect of the adrenergic system in the protection against SNP injury is not clear.

The adrenergic system plays an important role in neurological diseases, especially for mental illness, such as depression, and cerebral ischemia. The depressant effects of certain antipsychotic drugs appear to be mediated by the central adrenergic system $[9,10]$. One predominant biological response to acute stress is the release of norepinephrine, which activates the peripheral stress response and the hypothalamic-pituitary-adrenal (HPA) axis [11]. Partial $\beta 1$-adrenergic receptor agonists can be used for the treatment of neurocognitive disorders [12], and $\beta 2$-adrenergic receptor antagonists attenuate the brain damage induced by ischemia $[13,14]$.

Rat pheochromocytoma PC12 cells are typically used as models [15] for studying neuronal degeneration disorders such as Alzheimer's disease [16] and Parkinson's disease. They are also intensively used to investigate the reactive oxygen species (ROS) and NO synthase (NOS) [17] biochemical pathways involved in cell death and neuroprotection. Neuroblastoma SH-SY5Y cells, a cell line derived from human neuroblastomas, are also widely used in the study of the nervous system due to their cell growth and differentiation ability. Therefore, SNP-induced neurotoxicity in PC12 and SH-SY5Y cells are suitable to evaluate neuroprotective candidates. However, PC12 cells cannot produce adrenaline (AD), while SH-SY5Y cells can produce tyrosine hydroxylase, dopamine 2B2 hydroxylase, and dopamine transporters, which are characteristic of catecholaminergic neurons.

In view of the lack of research on whether the adrenergic system is involved in NO damage, we explored the effects of different adrenergic receptor agonists and antagonists in gradient doses on cell viability. We also researched the role of the $a$-adrenergic receptors and $\beta$-adrenergic receptors in the neuroprotective effect of ganoderic acid A on SNP injury.

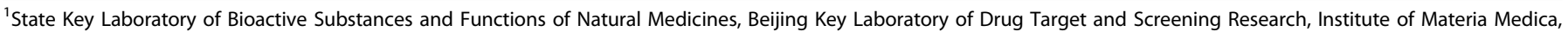
Chinese Academy of Medical Sciences and Peking Union Medical College, Beijing 100050, China
}

Correspondence: Guan-hua Du (dugh@imm.ac.cn)

Received: 18 June 2019 Accepted: 1 January 2020

Published online: 11 February 2020 


\section{MATERIALS AND METHODS}

Reagents

Ganoderic acid A (purity > 90\%) was isolated in the Department of Natural Medicinal Chemistry, Institute of Materia Medica, Chinese Academy of Medical Sciences, and the structure is shown in Fig. 1.

Metoprolol was purchased from Shanghai Dingkang Biomedical Materials Technology Co., Ltd. (China). DL-Adrenalin was purchased from Shanghai Yuanye Biotechnology Co., Ltd. (China). Phentolamine hydrochloride, ICI 118551, SNP, and 3-(4,5-dimethylthia-zol2-yl)-2,5-diphenyltetrazolium bromide (MTT) were purchased from Sigma-Aldrich Chemical Co. (St. Louis, MO, USA). Dulbecco's modified Eagle's medium (DMEM) and horse serum (HS) were obtained from Gibco Life Technologies Inc. (Grand Island, NY, USA). Fetal bovine serum (FBS) was purchased from PAN Seratech Co. (Aidenbach, Germany).

Cell culture and treatment

Both the SH-SY5Y and PC12 cell lines were obtained from the Cell Resource Center, Institute of Basic Medical Sciences, Chinese

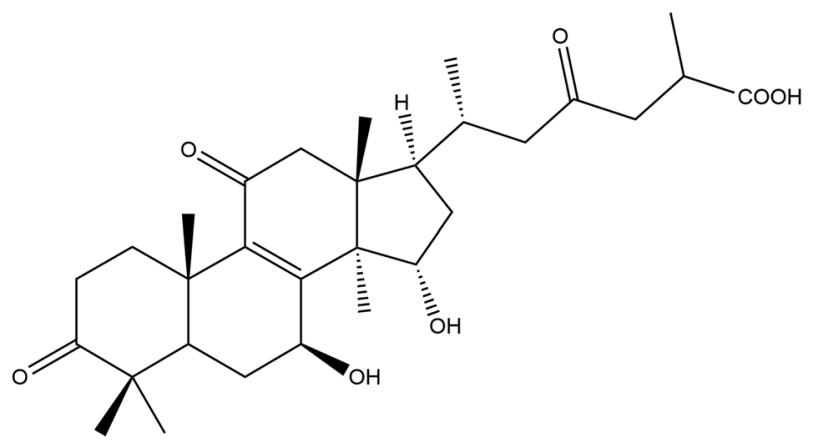

Fig. 1 The structure of ganoderic acid $A$.
Academy of Medical Sciences. SH-SY5Y cells were cultured in DMEM supplemented with $10 \% \mathrm{FBS}, 100 \mathrm{U} / \mathrm{mL}$ penicillin, and 100 $\mu \mathrm{g} / \mathrm{mL}$ streptomycin at $37^{\circ} \mathrm{C}$ in a $5 \% \mathrm{CO}_{2}$ atmosphere incubator, and PC12 cells were cultured in DMEM supplemented with $5 \%$ FBS, $5 \% \mathrm{HS}, 100 \mathrm{U} / \mathrm{mL}$ penicillin, and $100 \mu \mathrm{g} / \mathrm{mL}$ streptomycin. The medium was refreshed every 2 or 3 days.

The cells were collected when they had grown to $80 \%-90 \%$ confluence and were then treated with different concentrations of SNP for 12, 24, and $48 \mathrm{~h}$ to determine the optimal damage condition. After the SNP damage model was established, the cells were treated with SNP $(500 \mu \mathrm{M})$ for $24 \mathrm{~h}$ or were preincubated with ganoderic acid $\mathrm{A}$ at a $10 \mu \mathrm{M}$ concentration for $2 \mathrm{~h}$ before SNP exposure. The control group received equal-volume medium without SNP, and the model group was not preincubated with drugs. Different adrenergic receptor agonists and antagonists were separately added into the 96-well plates $1 \mathrm{~h}$ before ganoderic acid A preincubation to research the mechanism. Medium without SNP was added to the control group cells, and the model group received no preincubation with drugs. To properly choose suitable concentrations of adrenergic receptor agonists and antagonists, cells were treated with phentolamine, ICl 118551, metoprolol, and AD at concentrations of $0.1,1,3,10$, 30 , and $100 \mu \mathrm{M}$ for various intervals. Then, the cell viability was determined by the MTT method.

Determination of cell viability

To determine the cell viability, an MTT assay $(0.5 \mathrm{~g} / \mathrm{L})$ was conducted in a 96-well plate $\left(5 \times 10^{3} \mathrm{SH}-\mathrm{SY} 5 \mathrm{Y}\right.$ cells/wells and $8 \times 10^{3} \mathrm{PC} 12$ cells/wells) for $4 \mathrm{~h}$ at $37^{\circ} \mathrm{C}$ and incubated with the cells after $24 \mathrm{~h}$ of exposure to SNP. The dark blue formazan crystals formed in intact cells were solubilized in dimethyl sulfoxide and detected at $570 \mathrm{~nm}$ using a microplate reader.

Cell viability $(\%)=\left(A_{\text {experiment }}-A_{\text {blank }}\right) /\left(A_{\text {control }}-A_{\text {blank }}\right) \times 100 \%$. 

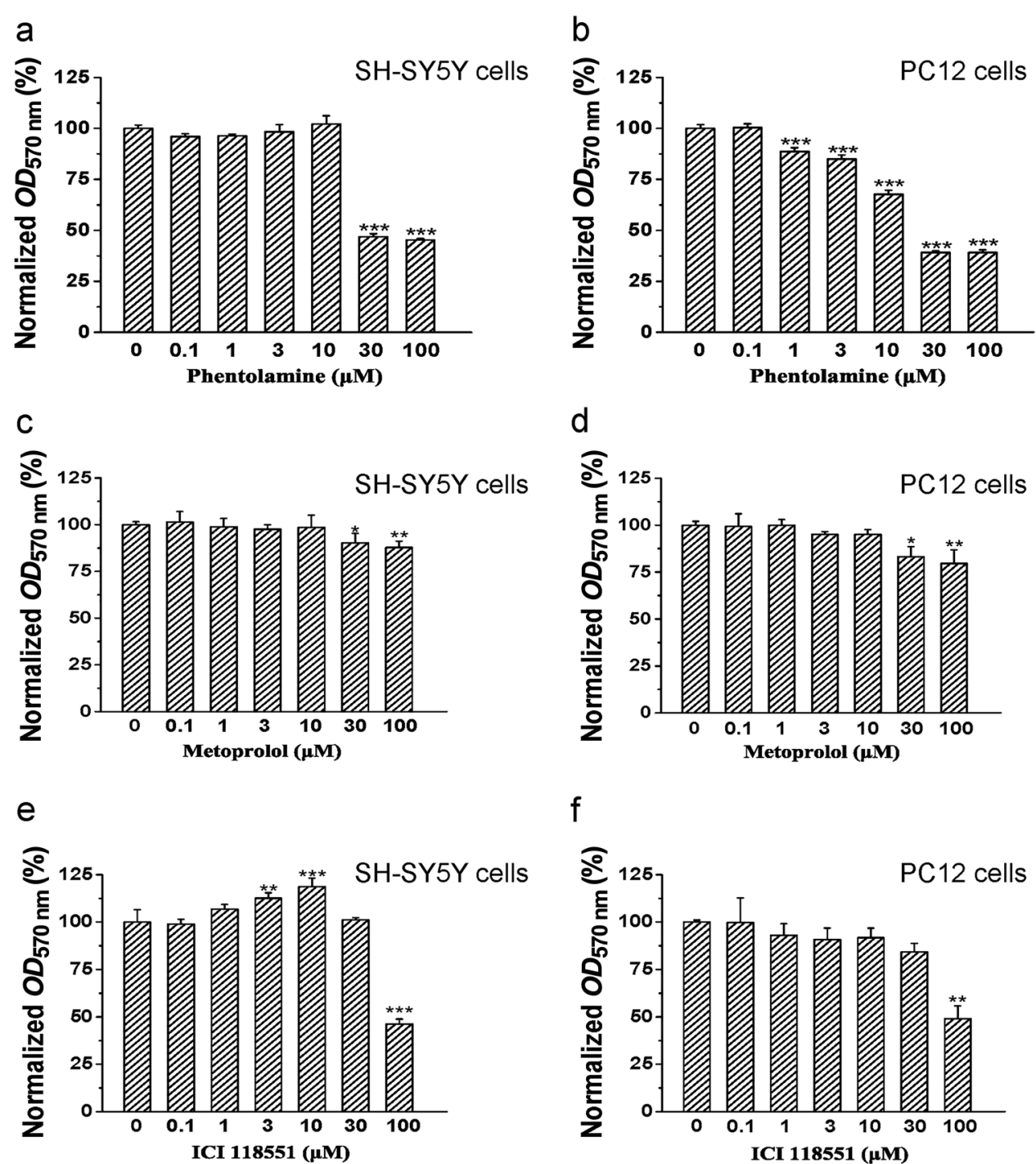

Fig. 3 The effects of different concentrations of adrenergic receptor antagonists on the viability of cells in $24 \mathrm{~h}$. Cells were exposed to various concentrations of phentolamine, metoprolol, and ICI 118551 for $24 \mathrm{~h}$. The viability was estimated by MTT assay and NO contents were detected using Griess reaction. a, b The effect of phentolamine on the viability of SH-SY5Y and PC12 cells; c, d effect of metoprolol on the viability of SH-SY5Ys and PC12 cells; e, $\mathbf{f}$ effect of ICI 118551 on the viability of SH-SY5Y and PC12 cells. Data were represented as the mean \pm SD from three independent experiments. ${ }^{*} P<0.05,{ }^{*} P<0.01$, and ${ }^{* * *} P<0.001$ as compared with control cells.

Assay of extracellular NO

The NO content was measured following the kit instructions using the Griess reaction. Sulfanilamide was added to the supernatant, and the mixture was incubated for $5 \mathrm{~min}$ at room temperature. Then, $\mathrm{N}$-1-naphthylethylenediamine dihydrochloride was added for another $5 \mathrm{~min}$ at room temperature, and the absorbance was measured at $540 \mathrm{~nm}$.

\section{Assay of cellular AD and NE}

The levels of $A D$ and NE were measured by enzyme-linked immunosorbent assay. After treatment, the cells in the 96-well plates were broken by lysates and centrifuged. The AD and NE levels in the supernatant were determined according to the guidelines of the kit by analysis on a microplate reader, and the maximum absorption peak was at $450 \mathrm{~nm}$. The AD and NE levels were calculated using a standard calibration curve and expressed in $\mathrm{pg} / \mathrm{mL}$.

Statistical analysis

All data were analyzed using the SPSS 22.0 software package and are expressed as the means \pm standard deviation (SD). In vitro results were analyzed by a $t$ test and one-way analysis of variance followed by Tukey's post hoc test. Probability $(P)$ values $<0.05$ were considered statistically significant.

\section{RESULTS}

AD induced cytotoxicity and increased NO contents in both SH-SY5Y and PC12 cells

We chose different concentrations of $A D$ at $0.1,1,3,10,30$, and $100 \mu \mathrm{M}$ to detect the cell viability and NO contents. As a result, 30 and $100 \mu \mathrm{M} \mathrm{AD}$ induced significant cytotoxicity in both SH-SY5Y and PC12 cells, and a high concentration of AD increased the NO content in the cell supernatant, which was similar to SNP injury (Fig. 2).

Adrenergic receptor antagonists induced cytotoxicity in both SH-SY5Y and PC12 cells

We chose different concentrations of phentolamine, metoprolol, and $\mathrm{ICI} 118551$ at $0.1,1,3,10,30$, and $100 \mu \mathrm{M}$ to detect the cell viability of SH-SY5Y and PC12 cells. As a result, phentolamine, 
a

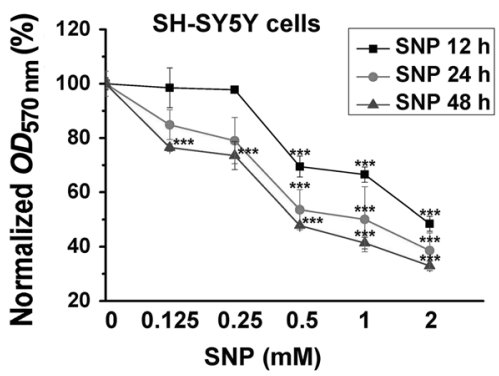

C

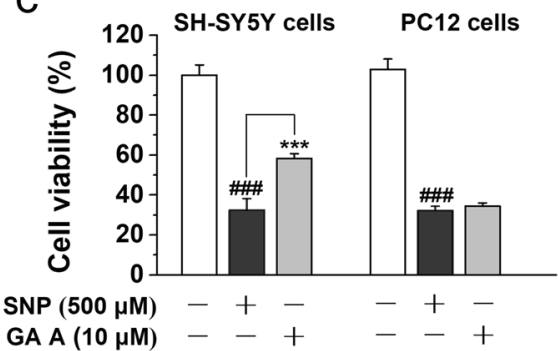

b

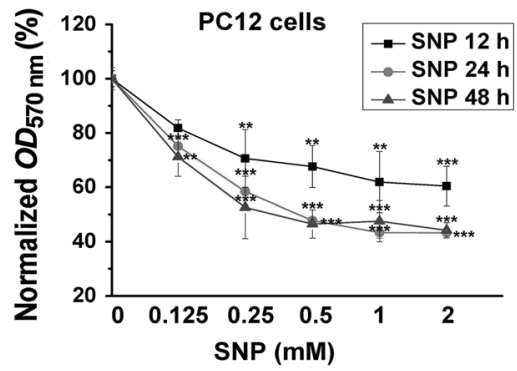

d

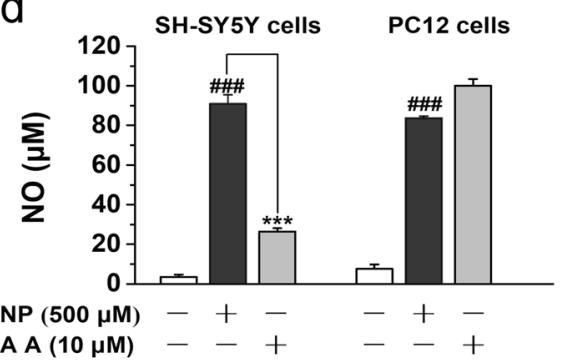

Fig. 4 The effects of ganoderic acid A on the viability and NO contents of SH-SY5Y and PC12 cells exposed to SNP. The viability was estimated by MTT assay and the NO contents were estimated using the supernatant of cell culture medium. $\mathbf{a}$, $\mathbf{b}$ The inhibitory effects of SNP on SH-SY5Y and PC12 cells; $\mathbf{c}$ effects of GA A on the viability of SH-SY5Y and PC12 cells exposed to SNP; $\mathbf{d}$ effects of GA A on the NO contents of SH-SY5Y and PC12 cells exposed to SNP. Data were represented as the mean \pm SD from three independent experiments. ${ }^{* *} P<0.01,{ }^{* * *} P<0.001$ as compared with control cells in $\mathbf{a}, \mathbf{b}$. ${ }^{\# \# \#} P<0.001$ as compared with control cells; ${ }^{* *} P<0.001$ as compared with SNP-exposed cells in $\mathbf{c}$, $\mathbf{d}$.
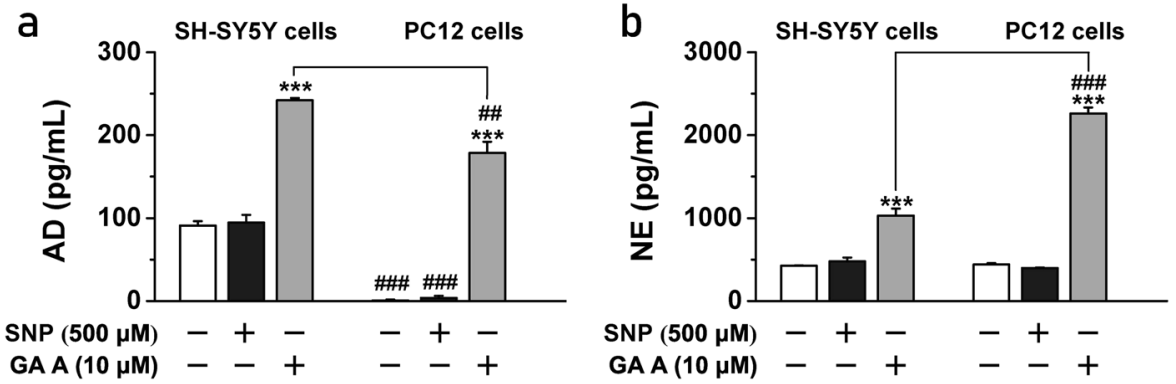

Fig. 5 The effects of ganoderic acid A on the AD and NE contents of SH-SY5Y and PC12 cells. Cells were exposed to SNP for 24 $\mathrm{h}$ with or without ganoderic acid A pretreatment at $10 \mu \mathrm{M}$ concentrations for $2 \mathrm{~h}$. The $A D$ and NE level was estimated using the supernatant of cell culture medium. a The effects of GA A on the AD content of SH-SY5Y and PC12 cells; $\mathbf{b}$ effects of GA A on the NE content of SH-SY5Y and PC12 cells. Data were represented as the mean \pm SD from three independent experiments. ${ }^{* * *} P<0.001$ as compared with control cells, ${ }^{\# \#} P<0.01$

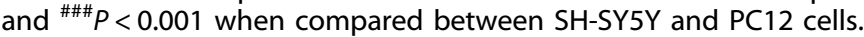

metoprolol, and ICI 118551 at high concentrations (especially 30 and $100 \mu \mathrm{M}$ ) all induced cytotoxicity significantly in both neural cell lines (Fig. 3).

Ganoderic acid A showed differences in cytotoxicity and NO contents between SH-SY5Y and PC12 cells

As shown in Fig. 4a, b, the damage caused by SNP showed a timeand dose-effect relationship on both SH-SY5Y and PC12 cells. The effect of SNP on cell viability increased as time and concentration increased. The cell viability decreased rapidly with the increase in the concentration of SNP from 0 to $500 \mu \mathrm{M}$, and then the degree of damage tended to be mild. The damage caused by SNP at $24 \mathrm{~h}$ was much more serious than that caused at $12 \mathrm{~h}$ at the same concentration, and the difference in damage between 48 and $24 \mathrm{~h}$ was not very significant. Therefore, we chose $500 \mu \mathrm{M}$ SNP for $24 \mathrm{~h}$ for our follow-up experiments, for which the cell viability was $53.61 \% \pm 7.37 \%$ and $47.82 \% \pm 0.86 \%$, respectively, for $\mathrm{SH}-\mathrm{SY} 5 \mathrm{Y}$ and PC12 cells.

Both cell lines were pretreated with ganoderic acid A $(10 \mu \mathrm{M})$ for $2 \mathrm{~h}$ prior to the $24-\mathrm{h}$ exposure to $500 \mu \mathrm{M}$ SNP to assess the protective effect. The viability of the cells pretreated with ganoderic acid A was significantly increased compared with SH-SY5Y cells treated with SNP alone, but the protective effect of ganoderic acid A on PC12 cells was not significant (Fig. 4c). SNP was used to induce the generation of NO. As shown in Fig. 4d, both SH-SY5Y and PC12 cells showed a significant increase in the supernatant NO level when exposed to SNP compared with the control group cells, and this effect was significantly ameliorated by pretreating SH-SY5Y cells with $10 \mu \mathrm{M}$ ganoderic acid A. However, the NO level was still high in PC12 cells.

Differences between SH-SY5Y and PC12 cells in the generation of $A D$ and $N E$ increased by ganoderic acid $A$

As shown in Fig. 5, the incubation of SH-SY5Y cells with SNP resulted in no significant difference in $A D$ and NE content compared with the control group cells. Ganoderic acid A significantly increased the generation of $A D$ and NE. Moreover, both the $A D$ and the NE content of ganoderic acid A-treated cells were significantly different in the two cell lines. The AD content was significantly higher in the SH-SY5Y cells than in the PC12 cells, 

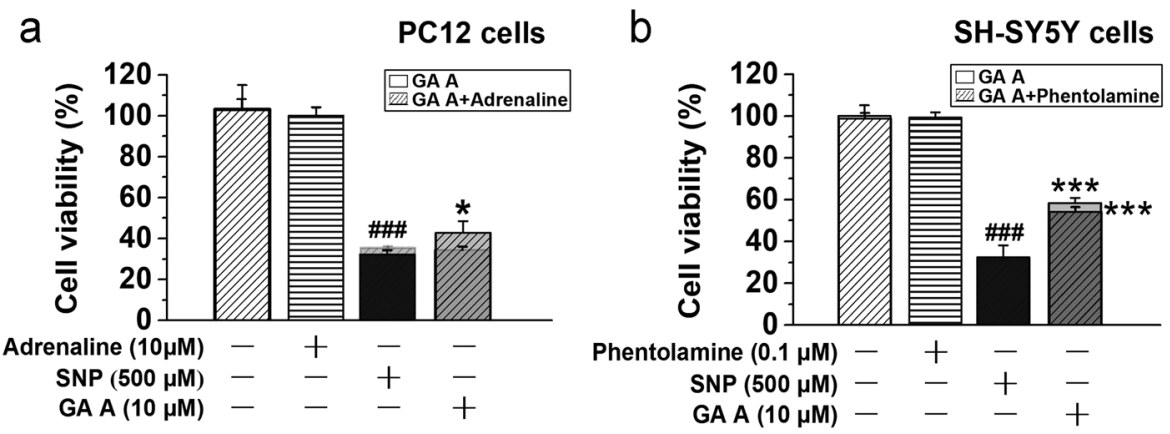

C

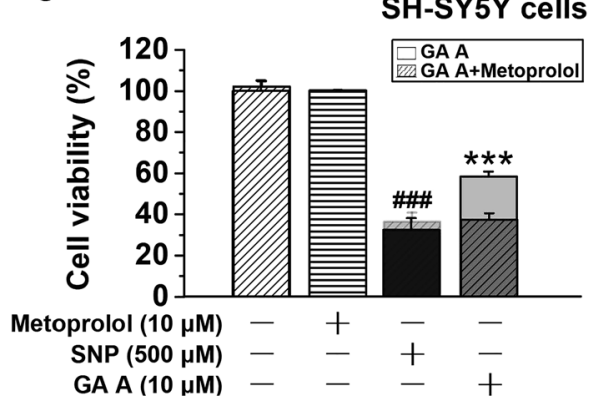

d

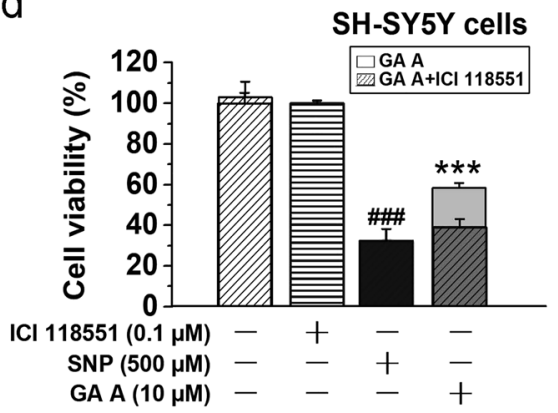

Fig. 6 Changes of different agonist and antagonists of adrenergic receptors on protective effect of ganoderic acid A. Cells were exposed to SNP for $24 \mathrm{~h}$ with or without GA A pretreatment at $10 \mu \mathrm{M}$ concentrations for $2 \mathrm{~h}$ and cells were preincubated with different agonist or antagonists for $1 \mathrm{~h}$ before GA A added into the cell culture fluid. The viability was estimated by MTT assay. a The effect of GA A co-incubated with adrenaline on cell viability of PC12 cells; $\mathbf{b}$ effect of GA A co-incubated with phentolamine on cell viability of SH-SY5Y cells; $\mathbf{c}$ effect of GA A co-incubated with metoprolol on cell viability of SH-SY5Y cells; d effect of GA A co-incubated with ICI 118551 on cell viability of SH-SY5Y cells. Data were represented as the mean \pm SD from three independent experiments. ${ }^{\# \#} P<0.001$ as compared with control cells, ${ }^{*} P<0.05$, as compared with SNP-exposed cells.

and the NE content was significantly higher in the PC12 cells than in the SH-SY5Y cells.

Different agonists and antagonists of adrenergic receptors changed the protective effect of ganoderic acid A

One of the differences between SH-SY5Y and PC12 cells is that $\mathrm{SH}$ SY5Y cells can synthesize epinephrine. AD is an agonist of the adrenal receptors, and we added AD to PC12 cells to retest the protective effect of ganoderic acid A on cell viability in SNP injury. As shown in Fig. 6a, AD $(10 \mu \mathrm{M})$ itself had no effect on the cell viability of PC12 cells. Ganoderic acid A showed a protective effect against SNP injury in PC12 cells when combined with AD.

Phentolamine is an antagonist of the a-adrenergic receptor. As shown in Fig. $6 \mathrm{~b}$, phentolamine $(0.1 \mu \mathrm{M})$ itself had no effect on the viability of SH-SY5Y cells. There was no significant difference in the protective effect of ganoderic acid A, which enhanced cell viability regardless of whether it was used alone or in combination with phentolamine.

Metoprolol is an antagonist of the $\beta 1$-adrenergic receptor, and ICI 118551 is an antagonist of the $\beta 2$-adrenergic receptor. As shown in Fig. $6 \mathrm{c}, \mathrm{d}$, metoprolol $(10 \mu \mathrm{M})$ and ICI $118551(0.1 \mu \mathrm{M})$ had no effect on the viability of SH-SY5Y cells. However, metoprolol and ICI 118551 blocked the protective effect of ganoderic acid A on SNP injury in SH-SY5Y cells.

\section{DISCUSSION}

The process of neural cell damage is often accompanied by an imbalance of the adrenergic system $[18,19]$. Some drugs acting on adrenergic receptors, such as $A D$ and isoproterenol, can induce myocardial injury $[20,21]$. Reduced $\beta$-adrenergic receptor ( $\beta$-AR) responsiveness could improve liver damage and myocardial injury [22], and a $\beta 2$-adrenergic receptor ( $\beta 2$-AR) agonist could aid in the recovery of ischemia-reperfusion injury [23]. SNP is a donor of NO; therefore, we established an excessive NO damage model induced by SNP to study the role of the adrenergic system in nerve injury [24-27].

In our experiments, $A D$ at low concentrations had little effect on the cell viability of both SH-SY5Y cells and PC12 cells, but AD at high concentrations significantly increased cell NO production and caused a significant reduction in cell viability, which was similar to the effect of SNP. Different adrenergic receptor antagonists all reduced cell viability at high concentrations. We found and confirmed that the excessive activation of the adrenergic system induced great damage to the nervous system, which made sense because many neurological diseases, such as Alzheimer's disease $[28,29]$ and depression $[30,31]$, involve changes in the adrenergic system. We give the most direct proof of the association between adrenergic receptors and SNP injury, which helps in the understanding of the role of the adrenergic system in neurological diseases.

The most important difference between SH-SY5Y and PC12 cells is that PC12 cells cannot produce AD, and ganoderic acid A showed significant protective effects on SH-SY5Y cells, but weak protective effects on $\mathrm{PC} 12$ cells. Furthermore, significant differences in $A D$ and $N E$ content between the two cell lines were detected. Therefore, we hypothesized that the adrenergic system participated in the protective effect of ganoderic acid A on $\mathrm{SH}$ SY5Y cells against SNP injury. We further supported this hypothesis by supplementing with AD and antagonizing $\alpha$ - or $\beta$ adrenergic receptors. Antagonists of a-adrenergic receptors are often used in the treatment of hypertension and urinary retention, work in the peripheral vasculature and inhibit the uptake of catecholamines in smooth muscle cells, resulting in vasodilation and blood pressure lowering [32]. Additionally, $\beta$-adrenergic receptors have often been researched in antihypertensive treatment [33], energy metabolism regulation [34], cardiovascular disease treatment [35], and anticancer treatment [36]. However, 
the adrenergic system has not drawn attention in the protection of the nervous system. What we found could effectively prove that the adrenergic system participated in the protection of neural cells against SNP injury, and this is also the highlight of our article.

It has been reported that $\beta$-adrenergic receptors are activated in long-term depression $[37,38]$, and antagonists can regulate depression [39] and show important significance during cerebral ischemia [40]; in addition, noradrenergic dysfunction has been found in Alzheimer's disease [41]. Neurological diseases are always accompanied by nerve injury. The damage mechanisms involve oxidative stress [42], mitochondrial damage [43], hypoxia-ischemia [44], neuroinflammation [45, 46], and other pathways. We believe that neurotransmitters of the adrenergic system also play an important role in the regulation of the nervous system but lack awareness. Our experiments proved that $\beta$-adrenergic receptors participated in the protective effect of ganoderic acid $A$ on neural cells, whereas a-adrenergic receptors had little effect on this process, but whether the $\beta$-adrenergic receptors participate in the other mechanisms of nerve damage and the detailed effects of different subtypes of adrenergic receptors still require further research.

\section{CONCLUSIONS}

The excessive $A D$ system had great damage to the nervous system, and $\beta$-adrenergic receptors played an important role in the protective effect of ganoderic acid A on SH-SY5Y cells against NO injury induced by SNP.

\section{ACKNOWLEDGEMENTS}

This project was supported by the CAMS Innovation Fund for Medical Sciences (201712M-1-010, China), the Drug Innovation Major Project (2018ZX09711001-003-005, China), and the Peking Union Medical College Graduate Innovation Fund Project (2017-1007-11).

\section{AUTHOR CONTRIBUTIONS}

ZRY and GHD designed research; ZRY performed research; HGY and GRH contributed new analytical tools; $\mathrm{CL}, \mathrm{HQW}$, and RYC contributed ganoderic acid A with high purity; ZRY, WHJ analyzed data; ZRY wrote the paper. All authors reviewed the manuscript.

\section{ADDITIONAL INFORMATION}

Competing interests: The authors declare no competing interests.

\section{REFERENCES}

1. Liu F, Yang $X$, Ma J, Yang $Y$, Xie C, Tuerhong $M$, et al. Nitric oxide inhibitory daphnane diterpenoids as potential anti-neuroinflammatory agents for $A D$ from the twigs of trigonostemon thyrsoideus. Bioorg Chem. 2017;75:149-56.

2. Jiménez-Jiménez FJ, Alonso-Navarro H, Herrero MT, García-Martín E, Agúndez JA. An update on the role of nitric oxide in the neurodegenerative processes of Parkinson's disease. Curr Med Chem. 2016;23:2666-79.

3. Ghashghaeinia $M$, Wesseling $M C$, Ramos $E$, Petkova-Kirova $P$, Waibel $S$, Lang $E$, et al. Trifluoperazine-induced suicidal erythrocyte death and s-nitrosylation inhibition, reversed by the nitric oxide donor sodium nitroprusside. Cell Physiol Biochem. 2017;42:1985-98.

4. Gupta SP, Kamal R, Mishra SK, Singh MK, Shukla R, Singh MP. Association of polymorphism of neuronal nitric oxide synthase gene with risk to Parkinson's disease. Mol Neurobiol. 2016;53:3309-14.

5. Wei J, Li $Y$, Jiao $Q$, DU $X X$, Jiang $H$. Influence of sodium nitroprusside on expressions of FBXL5 and IRP2 in SH-SY5Y cells. Acta Physiol Sin. 2017;69:261-6.

6. Nashida T, Takuma K, Fukuda S, Kawasaki T, Takahashi T, Baba A, et al. The specific $\mathrm{Na}^{+} / \mathrm{Ca}^{2+}$ exchange inhibitor SEA0400 prevents nitric oxide-induced cytotoxicity in SH-SY5Y cells. Neurochem Int. 2011;59:51-8.

7. Zhang J, Liu W, Wang Y, Zhao S, Chang N. MiR-135b plays a neuroprotective role by targeting GSK3 $\beta$ in MPP $^{+}$-intoxicated SH-SY5Y cells. Dis Markers. 2017;2017: $1-10$
8. Cardaci S, Filomeni G, Rotilio G, Ciriolo MR. Reactive oxygen species mediate p53 activation and apoptosis induced by sodium nitroprusside in SH-SY5Y cells. Mol Pharmacol. 2008;74:1234-45.

9. Gallager DW, Aghajanian GK. Effect of antipsychotic drugs on the firing of dorsal raphe cells. I. Role of adrenergic system. Eur J Pharmacol. 1976;39:341-55.

10. Dziedzicka-Wasylewska M, Farongórecka A, Rogóz Z, Solich J. The effect of combined treatment with imipramine and amantadine on the behavioral reactivity of central alpha1-adrenergic system in rats. Behav Pharmacol. 2004;15:159-65.

11. Gerritsen L, Milaneschi Y, Vinkers C, van Hemert AM, van Velzen L, Schmaal L, et al. HPA axis genes, and their interaction with childhood maltreatment, are related to cortisol levels and stress-related phenotypes. Neuropsychopharmacology. 2017;42:2446-55.

12. Yi B, Jahangir A, Evans AK, Briggs D, Ravina K, Ernest J, et al. Discovery of novel brain permeable and $G$ protein-biased beta-1 adrenergic receptor partial agonists for the treatment of neurocognitive disorders. PLoS ONE. 2017;12:e0180319.

13. Sun $Y$, Chen $X$, Zhang $X$, Shen $X$, Wang $M$, Wang $X$, et al. $\beta 2$-Adrenergic receptormediated HIF-1a upregulation mediates blood brain barrier damage in acute cerebral ischemia. Front Mol Neurosci. 2017;10:257. https://doi.org/10.3389/ fnmol.2017.00257.

14. White RE, Palm C, Xu L, Ling E, Ginsburg M, Daigle BJ, et al. Mice lacking the 2 adrenergic receptor have a unique genetic profile before and after focal brain ischaemia. ASN Neuro. 2012;4:e00096. https://doi.org/10.1042/AN20110020.

15. Dominiak A, Wilkaniec A, Wroczyński P, Jęśko $H$, Adamczyk A. Protective effects of selol against sodium nitroprusside-induced cell death and oxidative stress in PC12 cells. Neurochem Res. 2016;41:3215-26.

16. Kubota K, Fukue $H$, Sato $H$, Hashimoto $K$, Fujikane A, Moriyama $H$, et al. The traditional Japanese herbal medicine hachimijiogan elicits neurite outgrowth effects in PC12 cells and improves cognitive in AD model rats via phosphorylation of CREB. Front Pharmacol. 2017;21:850. https://doi.org/10.3389/fphar.2017.00850.

17. Lin D, Li X, Xu L, Lian J, Xu Y, Meng L, et al. Apogossypolone (ApoG2) induces ROS-dependent apoptosis and reduces invasiveness of PC12 cells in vitro and in vivo. Am J Transl Res. 2017;9:3990-4002.

18. Hamon $M$, Blier P. Monoamine neurocircuitry in depression and strategies for new treatments. Prog Neuropsychopharmacol Biol Psychiatry. 2013;45:54-63.

19. Le L, Nguyen TA. Therapeutic development of interrelated metabolic and neurodegenerative disorders. Curr Pharm Des. 2016;22:3608-18.

20. Mishra S, Chattopadhyay A, Naaz S, Ghosh AK, Das AR, Bandyopadhyay D. Oleic acid ameliorates adrenaline induced dysfunction of rat heart mitochondria by binding with adrenaline: an isothermal titration calorimetry study. Life Sci. 2019;218:96-111.

21. Eltobshy SAG, Hussein AM, Elmileegy AA, Askar MH, Khater $Y$, Metias EF, et al. Effects of heme oxygenase-1 upregulation on isoproterenol-induced myocardial infarction. Korean J Physiol Pharmacol. 2019;23:203-17.

22. Wasilewski MA, Grisanti LA, Song J, Carter RL, Repas AA, Myers VD, et al. Vasopressin type $1 \mathrm{~A}$ receptor deletion enhances cardiac contractility, $\beta$-adrenergic receptor sensitivity and acute cardiac injury-induced dysfunction. Clin Sci. 2016;130:2017-27.

23. Cameron RB, Gibbs WS, Miller SR, Dupre TV, Megyesi J, Beeson CC, et al. Proximal tubule $\beta 2$-adrenergic receptor mediates formoterol-induced recovery of mitochondrial and renal function after ischemia-reperfusion injury. J Pharmacol Exp Ther. 2019;369:173-80.

24. Muñoz M, Bermejo-Bescós P, Romero C, Benedí J, Martín-Aragón S. SNP-mediated neuroprotection under glucose deprivation is enhanced by hypericum perforatum. CNS Neurol Disord Drug Targets. 2012;11:162-73.

25. Antonic A, Dottori M, Macleod MR, Donnan GA, Howells DW. NXY-059, a failed stroke neuroprotectant, offers no protection to stem cell-derived human neurons. J Stroke Cerebrovasc Dis. 2018;27:2158-65.

26. Winter AN, Ross EK, Vamsi D, Sumner WA, Kirchhof DM, Manning E, et al. A cystine-rich whey supplement (Immunocal ${ }^{\circ}$ ) provides neuroprotection from diverse oxidative stress-inducing agents in vitro by preserving cellular glutathione. Oxid Med Cell Longev. 2017;2017:1-15.

27. Taram F, Winter AN, Linseman DA. Neuroprotection comparison of chlorogenic acid and its metabolites against mechanistically distinct cell death-inducing agents in cultured cerebellar granule neurons. Brain Res. 2016;1648:69-80.

28. Karczewski $P$, Hempel $P$, Bimmler M. Role of alpha1-adrenergic receptor antibodies in Alzheimer's disease. Front Biosci. 2018;23:2082-9.

29. Wu Q, Sun JX, Song XH, Wang J, Xiong CQ, Teng FX, et al. Blocking beta 2adrenergic receptor inhibits dendrite ramification in a mouse model of Alzheimer's disease. Neural Regen Res. 2017;12:1499-506.

30. Kokut S, Atay IM, Uz E, Akpinar A, Demirdas A. The polymorphisms of Ser49Gly and Gly389Arg in beta-1-adrenergic receptor gene in major depression. Noro Psikiyatr Ars. 2015;52:124-7.

31. Cottingham $C$, Wang $Q$. a2 adrenergic receptor dysregulation in depressive disorders: implications for the neurobiology of depression and antidepressant therapy. Neurosci Biobehav Rev. 2012;36:2214-25. 
32. de Araújo LJT, Nagaoka MR, Borges DR, Kouyoumdjian M. Participation of hepatic $\alpha / \beta$-adrenoceptors and AT1 receptors in glucose release and portal hypertensive response induced by adrenaline or angiotensin II. Braz J Med Biol Res. 2018;51: e7526.

33. Yang JW, Ye Y, Wang XR, Li F1, Xiao LY, Shi GX, et al. Acupuncture attenuates renal sympathetic activity and blood pressure via beta-adrenergic receptors in spontaneously hypertensive rats. Neural Plast. 2017;2017:8696402. https://doi. org/10.1155/2017/8696402.

34. Razzoli M, Emmett MJ, Lazar MA, Bartolomucci A. $\beta$-Adrenergic receptors control brown adipose UCP-1 tone and cold response without affecting its circadian rhythmicity. FASEB J. 2018;32:5640-6.

35. Zhang WB, Liu YQ, Zhang X, Lin L, Yin SL. The role of $\beta$-adrenergic receptors and p38MAPK signaling pathways in physiological processes of cardiosphere-derived cells: $\beta$-AR and p38MAPK signalings incardiosphere-derived cells. J Cell Biochem. 2018;119:1204-14.

36. Rains SL, Amaya CN, Bryan BA. Beta-adrenergic receptors are expressed across diverse cancers. Oncoscience. 2017:4:95-105.

37. Goh JJ, Manahan-Vaughan D. Hippocampal long-term depression in freely behaving mice requires the activation of beta-adrenergic receptors. Hippocampus. 2013;23:1299-308.

38. Hansen N, Manahan-Vaughan D. Locus coeruleus stimulation facilitates long-term depression in the dentate gyrus that requires activation of $\beta$-adrenergic receptors. Cereb Cortex. 2015;25:1889-96.
39. Stipica Safic I, Pecotic R, Pavlinac Dodig I, Dogas Z, Valic Z, Valic M. Phrenic longterm depression evoked by intermittent hypercapnia is modulated by serotonergic and adrenergic receptors in raphe nuclei. J Neurophysiol. 2018;120: 321-9.

40. Kulinskiĭ VI, Medvedeva TN. Significance of various types of adrenergic receptors for tolerance of the brain to complete ischemia. Biull Eksp Biol Med. 1996;121: 156-8.

41. Gannon M, Che P, Chen $Y$, Jiao K, Roberson ED, Wang Q. Noradrenergic dysfunction in Alzheimer's disease. Front Neurosci. 2015;9:220. https://doi.org/ 10.3389/fnins.2015.00220.

42. Head E, Rofina J, Zicker S. Oxidative stress, aging and CNS disease in the canine model of human brain aging. Vet Clin N Am Small Anim Pract. 2008;38: 167-78.

43. Li MX, Mu DZ. Mitophagy and nervous system disease. Chin J Contemp Pediatr. 2017;19:724-9.

44. Liu HT, Mu DZ. Inducible nitric oxide synthase and brain hypoxic-ischemic brain damage. Chin J Contemp Pediatr. 2014;16:962-7.

45. Andres RH, Choi R, Pendharkar AV, Gaeta X, Wang N, Nathan JK, et al. The CCR2/ CCL2 interaction mediates the transendothelial recruitment of intravascularly delivered neural stem cells to the ischemic brain. Stroke. 2011;42:2923-31.

46. Virga DM, Capps J, Vohra BPS. Enteric neurodegeneration is mediated through independent neuritic and somal mechanisms in rotenone and $\mathrm{MPP}^{+}$toxicity. Neurochem Res. 2018;43:2288-303. 